\section{Carbon Monoxide Poisoning}

The number of deaths from carbon monoxide $(\mathrm{CO})$ poisoning remained constant for many years but has recently started to fall. There are three reasons. Firstly, it has become more fashionable to commit suicide by more sophisticated methods, particularly now that tranquillisers and antidepressants are widely prescribed. Secondly, Britain's domestic gas supply is being changed over from coal gas to natural gas, which contains no carbon monoxide-though so far only an eighth of the country has actually been converted to the new gas. Thirdly, and perhaps most significant, is the changeover which has taken place in the manufacture of gas for domestic use, coal carbonization having given way to oil reforming. Techniques for reducing the amount of $\mathrm{CO}$ present have also been introduced, but as G. Thurston ${ }^{1}$ has shown, inadequate combustion or ventilation can be lethal even when the original fuel contains no CO. So in about eight years, when the whole country has been converted to natural gas, there will still be numbers of patients with $\mathrm{CO}$ poisoning needing resuscitation.

Recently J. S. Smith and S. Brandon ${ }^{2}$ reviewed 206 episodes of $\mathrm{CO}$ poisoning in Newcastle. The mortality rate was $39 \%$. In $20 \%$ of patients recovery was complicated by prolonged delirium suggesting that "all degrees of functional or structural neurological damage may have occurred, yet oxygen therapy was given in only $43.8 \%$ of suicidal and $32.5 \%$ of accidental exposures." They suggest that in view of the risk of persistent neuropsychiatric sequelae current patterns of management should be revised.

In selecting a form of therapy there are two aspects to consider: firstly, the prevention of death and, secondly, the reduction of neuropsychiatric sequelae such as those described by $\mathrm{H}$. Garland and J. Pearce. ${ }^{3}$ Carboxyhaemoglobin should be eliminated as quickly as possible because its presence alters the dissociation curve of the remaining oxyhaemoglobin, impeding oxygen release to the tissues. ${ }^{4}$

J. S. Haldane ${ }^{5}$ was the first to describe the use of hyperbaric oxygen in $\mathrm{CO}$ poisoning, when he failed to poison a mouse placed in a jar containing two atmospheres of oxygen and one of CO. This was all the more remarkable for the fact that the affinity of haemoglobin for $\mathrm{CO}$ is about 250 times that for oxygen. Hyperbaric oxygen keeps the patient's tissues oxygenated by the oxygen physically dissolved in the plasma at a time when his haemoglobin is not available to him for oxygen transpcrt. It is also the most efficient means of reducing the carboxyhaemoglobin level, as was shown by T. A. Douglas and his colleagues ${ }^{6}$ in 1962 when they compared the efficiencies of oxygen at one atmosphere's pressure, oxygen at two atmospheres' pressure, and of 5\% and 7\% carbon dioxide in oxygen.

Doctors confronted with a patient suffering from $\mathrm{CO}$

1 Thurston, G., Medico-Legal fournal, 1968, 36, 191.

2 Smith, J. S., and Brandon, S., Postgraduate Medical fournal, 1970, 46, 65. 3 Garland, H., and Pearce, J., Quarterly fournal of Medicine, 1967, 36, 445.

4 Douglas, C. G., Haldane, J. S., and Haldane, J. B. S., Fournal of Physiology, $1912,44,275$

5 Haldane, J. S., Fournal of Physiology, 1895, 18, 201.

6 Douglas, T A et al, Lancet, 1962, 1, 68 .

Matthew, H., and Lawson, A. A. H., Treatment of Common Acute Poison ings, 2nd edn. Edinburgh, Livingstone, 1970.

${ }^{8}$ Norman, J. N., MacIntyre, J., Shearer, J. R., and Smith, G., British Medical fournal, 1970, 2, 333.

*Hospitals offering hyperbaric oxygen for clinical use: Derbyshire Roya Infirmary, Derby; Fairfield's General Hospital, Bury, Lancs; Frenchay Hospital, Bristol; Good Hope Hospital, Sutton Coldfield; Heatherwood Hospital, Ascot, Berks; The London Hospital, Whitechapel; The Monsall Hospital, Manchester; Peterborough and District Hospital, Peterborough; Preston Hall Chest Hospital, Maidstone; Princess Alexandra's Hospital, R.A.F. Wroughton; Royal Hampshire County Hospital, Winchester; Royal N.A.F. Wroughton; Royal Hampshire County Hospital, Winchester; Royal Grinstead; University College Hospital, London; Western Infirmary, Grinstead; University College Hospital, London; Western Infirmary, Glasgow; Westminster Hospital, L poisoning should, then, treat the patient by the means most effective in reducing the level of carboxyhaemoglobinhyperbaric oxygen-and this is true of all levels of $\mathrm{CO}$ poisoning. Until the patient is placed in the hyperbaric atmosphere $95 \%$ oxygen and $5 \%$ carbon dioxide should be given, together with intravenous hypertonic mannitol, as advocated by H. Matthew and A. A. H. Lawson.?

Some centres in Britain at which treatment with hyperbaric oxygen is available are listed at the foot of the page.* There is in addition a mobile chamber based at Aberdeen, which has recently been used effectively. ${ }^{8}$

\section{Too Much Protection?}

Sixty years ago the hazards of radiation were largely ignored. Forty years ago there was concern for the safety of radiation workers in hospitals and in industry. Fifteen years ago the debate on danger to the public from nuclear weapon tests and from diagnostic radiology was approaching its crescendo. Today it is generally agreed that the risks of radiation are effectively controlled. It has, indeed, been suggested that current British practice is unduly strict and that the effort entailed in measuring and recording the small doses of radiation incurred by the great majority of $x$-ray workers is not justified.

The maximum permissible dose for radiation workers is 5 rems per year. In practice, considerably lower exposures can be achieved without hindering the work of clinical departments. Information published by the Radiological Protection Service for the years $1963-6^{1}$ showed that only $0 \cdot 1 \%$ of hospital radiation workers received more than 5 rems and only $1.3 \%$ (mainly in radiotherapy departments) more than 1.5 rems per year. The average annual dose was less than $0.4 \mathrm{rem}$, which may be compared with the natural background of about $0 \cdot 1 \mathrm{rem}$.

The International Commission on Radiological Protection recommends ${ }^{2}$ that individual monitoring, personal dose records, and special health supervision are not required for radiation workers unlikely to incur doses exceeding $1.5 \mathrm{rems}$ per year. It has been authoritatively suggested ${ }^{1}$ that there is little merit in continuing routine medical supervision and maintaining detailed dose records for the majority of radiation workers and ${ }^{3}$ that there is "no justification for the waste of space and of time involved in keeping individual lifetime records of exposure at this level."

But Britain's way of controlling radiation hazards in hospitals is the envy of the world and should not be abandoned merely because it has proved very successful. The regular use of personal film badges provides the simplest reliable method for environmental monitoring and should be continued. ${ }^{4} \mathrm{At}$ the same time, dose recording procedures and additional medical supervision might well be simplified for the great majority of hospital radiation workers (more than $99 \%$ of those in diagnostic $x$-ray departments), whose dose levels are below 1.5 rems per year. The effort released in this way might be better used in identifying and instructing the small number of radiological departments in which arrangements for the protection of staff from radiation hazards do not reach the high standard now commonly prevailing.

\footnotetext{
Duggan, M. J., Greenslade, E., and Jones, B. E., Nature, 1969, 221, 831. International Commission on Radiological Protection, Radiation Protection: Recommendations. Oxford, Pergamon, 1966.

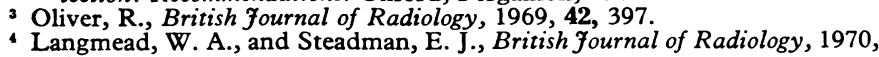
43, 279 .
} 